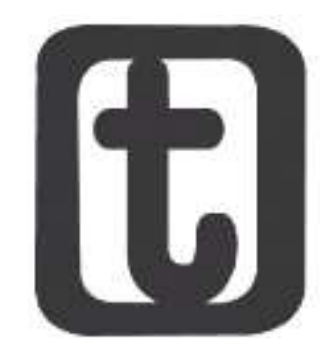

\title{
TRABALHADORES ASSISTENTES SOCIAIS EM TEMPOS DE ACIRRAMENTO DA PRECARIZAÇÃO DO TRABALHO
}

\author{
Social workers in the times of exacerbation of the precarisation of work \\ Flávia Barbosa Pardini dos Santos* \\ Inez Stampa**
}

\begin{abstract}
RESUMO
Este artigo aborda categorias e conceitos que fundamentam a assertiva de que o Serviço Social é trabalho e, tendo como premissa a acepção de que o trabalho possui centralidade na vida humana, menciona a ofensiva neoliberal que incide sobre o conjunto dos trabalhadores, apresentando formas contemporâneas de espoliação dos trabalhadores assistentes sociais no cenário brasileiro. Assevera que a análise das relações e condições de trabalho do assistente social na atual conjuntura torna-se imprescindível para desvelar a exploração imiscuída nesse processo. Utilizando-se de revisão bibliográfica, apresenta reflexões sobre o tempo presente, marcado pela exacerbação do conservadorismo e retrocessos que também impactam o Serviço Social e seus operadores, o que requer a pesquisa como um imperativo para a elaboração de propostas estratégicas, criativas e transformadoras.
\end{abstract}

\section{PALAVRAS-CHAVE}

Serviço Social. Trabalho. Precarização. Trabalhadores assistentes sociais.

\section{ABSTRACT}

This article approaches concepts that underlie the assertion that Social Work is work and, based on the premise that the work has centrality in human life, it mentions the neoliberal offensive that affects all workers, presenting contemporary forms of spoliation of social workers in the Brazilian scenery. He asserts that the analysis of the relations and conditions of work of the social worker in the current conjuncture becomes essential to unveil the exploitation immersed in this process. This article presents reflections on the present time, marked by the expansion of conservatism and setbacks that also impact Social Work and its operators, requires research as an imperative for the elaboration of strategic, creative and transformative proposals.

\footnotetext{
* Assistente Social. Mestre em Serviço Social. Assistente Social da Diretoria de Assistência Social (DAS) da Polícia Militar do Estado do Rio de Janeiro (PMERJ, Rio de Janeiro, Brasil). Rua Francisco Eugênio, 228, São Cristovão, Rio de Janeiro (RJ), CEP: 20941-120. ORC ID: http://orcid.org/0000-0003-4872-7543. E-mail: <flavia.riqueza@gmail.com>.

** Assistente Social. Doutora em Serviço Social pela PUC-Rio. Professora do Departamento de Serviço Social e do Programa de Pós-graduação em Serviço Social da Pontifícia Universidade Católica do Rio de Janeiro (PUC-Rio, Rio de Janeiro, Brasil). Rua Marquês de São Vicente, 225, Gávea, Rio de Janeiro (RJ), CEP: 22451900. Coordenadora Adjunta da área de Serviço Social da Capes. Bolsista de Produtividade em Pesquisa CNPq. ORC ID: http://orcid.org/0000-0003-3770-1129. E-mail:<inestampa@ig.com.br>.
}

\section{DOI 10.22422/temporalis.2019v19n37p84-101}

(cc) $\mathrm{Br}$ Commons Atribuição 4.0 Internacional (https://creativecommons.org/licenses/by/4.o/deed.pt_BR), que permite copiar e redistribuir o material em qualquer suporte ou formato, bem como adaptar, transformar e criar a partir deste material para qualquer fim, mesmo que comercial. O licenciante não pode revogar estes direitos desde que você respeite os termos da licença.

Temporalis, Brasília (DF), ano 19, n. 37, p. 84-101, jan./jun. 2019. | ISSN 2238-1856 


\section{KEYWORDS}

Social Work. Work. Precariousness. Social workers.

\section{INTRODUÇÃO}

$E^{s}$ ste artigo objetiva discutir as relações e condições de trabalho dos assistentes sociais no contexto brasileiro atual, analisando mudanças nesse campo que reverberam sobre o exercício profissional e os desafios que estão postos a estes profissionais no tempo presente. Para a reflexão pretendida, pauta-se em categorias como trabalho e precarização do trabalho, estabelecendo relações com a temática do trabalhador assistente social.

Orientado pela teoria crítica marxiana, o estudo busca apreender, através de revisão bibliográfica, as recentes transformações que ocorrem no mundo do trabalho (STAMPA, 2012) e seus rebatimentos nos diferentes espaços sócio-ocupacionais em que se inserem os assistentes sociais. Nesse horizonte, manteve-se apoiado na perspectiva de que essas relações de trabalho estabelecidas cotidianamente são estrategicamente implementadas pelo plano político-econômico que vem sendo adotado no país.

A conjuntura atual se encontra permeada de retrocessos que incidem diretamente sobre o conjunto da classe trabalhadora. É um tempo marcado pelo recrudescimento da contrarreforma do Estado para atender aos interesses da classe dominante, o que exige, cada vez mais, a regressão de direitos dos trabalhadores.

Contextualizando o campo dos direitos sociais do trabalho, pode-se afirmar que está posto um verdadeiro ataque aos direitos legalmente instituídos, os quais se constituem fruto de intensa mobilização dos trabalhadores. Assiste-se a um movimento permeado de articulações político-econômicas que ditam uma nova ordem, que implica na redução do Estado para os trabalhadores e sua livre apropriação pelo capital. Capitaneado pelos interesses da burguesia, o Estado, ainda que permeado por contradições próprias do modo de produção capitalista, se torna lócus do mercado, institucionalizando novos mecanismos de exploração da força de trabalho e mercantilização das políticas públicas.

O processo de reestruturação produtiva no Brasil, portanto, segue acompanhado de pressões por flexibilização nas relações do trabalho, como ação indispensável à oferta de empregos e desenvolvimento econômico, como quer fazer crer a narrativa das classes hegemônicas. Esse discurso fetichizado, no entanto, encobre o real interesse do mercado, que é ampliar suas bases de lucro através de sua fonte matricial: o trabalho. Assim é que se observam tendências atuais para mais intensificação do trabalho, configurando um contexto de verdadeira barbárie social.

Em face desta perspectiva, compreende-se que os assistentes sociais, aqui entendidos enquanto sujeitos trabalhadores, inseridos nos diferentes espaços sócio-ocupacionais, são também acometidos pelo processo de reestruturação produtiva. Este interfere em suas condições de trabalho, assim como nos processos de trabalho em que se encontram inseridos. A intensificação e a precarização do trabalho, ou melhor, as diversas alterações degradantes no universo do trabalho, atingem direta e/ou indiretamente o trabalhador assistente social. 


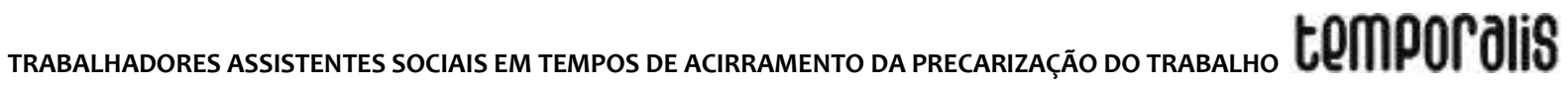

Dessa forma, o estudo ora apresentado, com base em reconhecidos autores que abordam a temática, defende que o Serviço Social é trabalho. Por conseguinte, e de maneira introdutória, apresenta o debate sobre as relações de trabalho dos assistentes sociais na atualidade, no sentido de enfocar suas condições de trabalho nesse contexto de intensificação da precarização e regressão de direitos.

O entendimento de que o trabalho ocupa lugar central na vida do ser humano nos impeliu à busca pelo conhecimento dos diferentes aspectos que determinam as relações de trabalho dos assistentes sociais na contemporaneidade. Assim, foram buscadas interfaces entre o cenário político-econômico atual e os desafios que estão postos aos trabalhadores assistentes sociais nesse contexto de profundas transformações societárias.

Dessa forma, são apresentadas reflexões sobre a importância da pesquisa como um imperativo, no contexto atual, para se desvelar os processos sutis, reacionários e conservadores que incidem sobre o trabalho do assistente social. Considera-se que a análise sobre a realidade concreta vivida por esses trabalhadores é essencial, já que o processo de reestruturação produtiva desencadeado no país nos impõe novos desafios tanto no âmbito técnico-operativo, quanto no plano do conhecimento.

\section{A CATEGORIA TRABALHO E O SERVIÇO SOCIAL: MEDIAÇÕES NECESSÁRIAS}

Sem sombra de dúvida, a vontade do capitalista consiste em encher os bolsos, o mais que possa. E o que temos a fazer não é divagar acerca de sua vontade, mas investigar o seu poder, os limites desse poder e o caráter desses limites. (MARX, 1985, p. 59)

De início, assevera-se que o Serviço Social, enquanto atividade inserida nas relações sociais de produção se encontra no campo dos serviços, os quais são intangíveis, porém integram o circuito das relações sociais produtivas de acumulação do capital. Trata-se do trabalho abstrato que, embora seja considerado como trabalho improdutivo, por não compor, diretamente, a produção material, são os serviços que agregam valor ao produto no processo de produção capitalista.

Para Marx, tanto a atividade concreta quanto a abstrata inserida nas relações sociais de produção material, se constituem trabalho e, portanto, são dotadas de valor. O trabalho é o único elemento que gera valor nessa relação orgânica do capital, e é o tempo dispensado para a produção de uma mercadoria que vai determinar o seu valor. Ou seja:

Se, no entanto, o mesmo trabalhador mudar de profissão e se tornar marceneiro, agregará, depois como antes, valor a seu material mediante uma jornada de trabalho. Agrega valor, portanto, mediante seu trabalho não por ser trabalho de fiação ou de marcenaria, mas por ser trabalho abstrato, social geral, e agrega determinada grandeza de valor não por ter seu trabalho um conteúdo particular, útil, mas porque dura um tempo determinado. Portanto, em virtude de sua propriedade abstrata, geral, como dispêndio de força de trabalho humana, o trabalho do fiandeiro agrega novo valor aos valores do algodão e do fuso, e em virtude de sua propriedade concreta, específica, útil, como processo de fiação, transfere o valor aos valores do algodão e do fuso, e em virtude de sua propriedade concreta, específica, útil, como processo de fiação concreta, específica, útil, como processo de fiação, transfere o valor desses meios de produção ao produto e recebe assim seu valor no produto (MARX, 1985, p. 166).

Temporalis, Brasília (DF), ano 19, n. 37, p. 84-101, jan./jun. 2019. | ISSN 2238-1856 
A diferença substancial entre trabalho produtivo e trabalho improdutivo se encontra na premissa marxiana que distingue o trabalho que gera um produto para a satisfação das necessidades humanas, isto é, dotado de valor de uso, do trabalho que gera lucro, mais valia, no processo de acumulação do capital. Assim, para Marx (1978):

Todo trabalhador produtivo é assalariado, mas nem todo assalariado é trabalhador produtivo. Quando se compra o trabalho para consumi-lo como valor de uso, como serviço, - e não para colocá-lo como fator vivo em lugar do valor do capital variável e incorporá-lo ao processo capitalista de produção -, o trabalho não é trabalho produtivo e o trabalhador assalariado não é trabalhador produtivo. Seu trabalho é consumido por causa de seu valor de uso, não como trabalho que gera valores de troca; consome-se-o improdutiva, não produtivamente. (MARX, 1978, p. 72, grifos do autor).

Mais adiante, Marx (1978, p.73) esclarece esta assertiva:

Assim como as mercadorias que o capitalista compra para consumo privado não são consumidas produtivamente, não se transformam em fatores do capital, tampouco isso ocorre com os serviços que compra para seu consumo por vontade própria ou forçado (ao Estado etc.), por causa do seu valor de uso. Eles não se convertem em fator do capital. Por conseguinte não são trabalhos produtivos e seus executantes não são trabalhadores produtivos. (MARX, 1978, p. 73, grifos do autor).

Os serviços, portanto, correspondem a trabalhos que não se separam dos seus trabalhadores, como um produto material (MARX, 1978). Esse trabalho abstrato, no entanto, pode se constituir produtivo ou improdutivo, a depender das condições objetivas em que este trabalho se opera. Tal fato é elucidado nas colocações marxianas:

\footnotetext{
Um trabalho [...] pode ser, portanto, produtivo e improdutivo. [...] Uma cantora que entoa como um pássaro é um trabalhador improdutivo. Na medida em que vende seu canto, é assalariada ou comerciante. Mas, a mesma cantora, contratada por um empresário (entrepreneur), que a faz cantar para ganhar dinheiro, é um trabalhador produtivo, já que produz diretamente capital (MARX, 1978, p. 76, grifos do autor).
}

Assentada nesse fundamento, a adoção do conceito que defende a profissão como uma especialização do trabalho, portanto, se constitui um marco no Serviço Social. Esta nova concepção busca consolidar o rompimento com o histórico conservadorismo que permeou o exercício profissional dos assistentes sociais (IAMAMOTO; CARVALHO, 1991). De outro ângulo, transfere a objetividade social do trabalho dos assistentes sociais a outros interesses vinculados a uma classe, a classe trabalhadora.

Nas palavras de lamamoto e Carvalho (1991):

Como trabalhador assalariado, o Assistente Social aparece como produtor de serviços - não diretamente produtivos - que são, no entanto, necessários à existência e maior produtividade dos trabalhos diretamente produtivos, fato no qual coincide com outras tantas funções técnicas. (IAMAMOTO; CARVALHO, 1991, p. 272, grifos dos autores). 


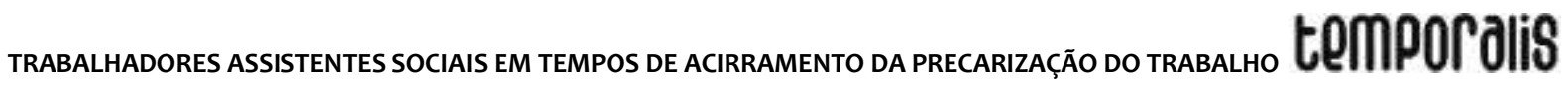

Desse modo, cabe registrar que esse entendimento tem sua origem no ano de 1982, impulsionado através das reflexões contidas na obra Relações Sociais e Serviço Social no Brasil: esboço de uma interpretação histórico-metodológica de lamamoto e Carvalho (1991).

A partir das provocações teóricas ensejadas pela aproximação entre o Serviço Social e o marxismo, apresentadas no referido livro, o debate sobre o tema se intensificou no seio da categoria. Nessa medida, uma importante expressão do reconhecimento de que o Serviço Social é uma especialização do trabalho, por parte dos assistentes sociais inseridos no contexto brasileiro, foi a inserção deste conceito nas Diretrizes Curriculares para o curso de graduação em Serviço Social pela Associação Brasileira de Ensino de Serviço Social (ABESS), no ano de 1996 (CARVALHO, 2016), que, no mesmo ano, passou a se chamar Associação Brasileira de Ensino e Pesquisa em Serviço Social (ABEPSS). ${ }^{1}$ Cabe registrar, este fato construído por meio do processo de renovação curricular, representou uma significativa inovação no Serviço Social.

Esta acepção, no entanto, não é absoluta na profissão. Apesar de sua sólida fundamentação teórica, existem outros autores que, pautando-se num entendimento diverso, defendem que o Serviço Social não é trabalho.

Partilham dessa última perspectiva autores como Sergio Lessa (2000, 2012), Gilmaísa M. da Costa $(2000,2011)$, dentre outros, os quais defendem que o Serviço Social não é trabalho porque não realiza o intercâmbio orgânico com a natureza; não a transforma em bens materiais necessários à reprodução social.

Lessa (2012) afirma que "[...] a vertente que identifica o Serviço Social como trabalho o faz em razão de sua aproximação com as Ciências Humanas" (LESSA, 21012, p. 16). O autor, contudo, faz a distinção entre a práxis dos operários e a práxis dos assistentes sociais, destacando que, quanto a estes últimos, realizam a mediação da ideologia junto a outros indivíduos; na sua atividade profissional não há matéria prima, nem um "[...] produto final [...]" (LESSA, 2012, p. 66), o que os diferem dos primeiros.

Ou seja, como a atividade profissional dos assistentes sociais não corresponde à transformação da natureza, está inserida em um complexo social, ideológico, atuando na organização da vida social para efetivar a produção.

Assim, Lessa (2012, p.72), afirma que:

O assistente social, portanto, não apenas não 'trabalha' como o operário, como ainda é um 'trabalhador' distinto do operário [...] suas práxis são muito distintas; atendem a funções sociais muito diferenciadas e, além disso, pertencem a distintas classes sociais [...] o assistente social pertence às 'classes de transição' cumpre, portanto, uma função social diversa, na reprodução da sociedade burguesa, da do proletariado (LESSA, 2012, p. 72).

\footnotetext{
'A mudança do nome da ABESS para Associação Brasileira de Ensino e Pesquisa em Serviço Social (ABEPSS) se explica no entendimento de que o ensino, a pesquisa e a extensão são indissociáveis. A inovação está assentada ainda, na "[...] articulação entre graduação e pós-graduação, aliada à necessidade da explicitação da natureza científica da entidade, bem como a urgência da organicidade da pesquisa no seu interior, hoje por meio dos Grupos Temáticos de Pesquisa e da Revista Temporalis" (ASSOCIAÇÃO BRASILEIRA DE ENSINO E PESQUISA EM SERVIÇO SOCIAL, O2019).
}

Temporalis, Brasília (DF), ano 19, n. 37, p. 84-101, jan./jun. 2019. | ISSN 2238-1856 
Sob outra ótica, lamamoto (1999) destaca que "[...] o trabalho do assistente social tem um efeito nas condições materiais e sociais [...]" (IAMAMOTO, 1999, p. 67) dos usuários dos seus serviços. Isso ocorre, essencialmente, por meio da prestação dos serviços sociais à população. Desta forma, o trabalho do assistente social é partícipe do processo de produção e reprodução da força de trabalho, na medida em que através de sua atividade, contribui, no processo coletivo, com a produção do valor e, consequentemente, com a dinâmica de acumulação do capital.

Para além do trabalho do assistente social que resulta num determinado produto concreto, o Serviço Social possui uma objetividade que é social. Através do seu trabalho, o assistente social não trabalha somente com a viabilização do acesso aos recursos materiais necessários para o atendimento das necessidades básicas dos usuários do Serviço Social. Sua atuação também incide sobre o conhecimento, sobre os valores, sobre a cultura, enfim, sobre a vida dos sujeitos com os quais lida no seu cotidiano de trabalho (IAMAMOTO, 1999).

A partir dessas inferências, pode-se aduzir que é nessa relação complexa entre trabalho concreto e trabalho abstrato, intrínseca à lógica capitalista, nas relações sociais de produção, que o Serviço Social se constitui socialmente necessário para a realização do trabalho coletivo.

Nesse prisma, a compreensão da profissão Serviço Social se perfila como uma especialização do trabalho coletivo, instituída historicamente como atividade auxiliar para desempenhar o papel de intermediador entre os interesses dos trabalhadores e da classe dominante, sendo seu papel principal o de legitimar os interesses desses últimos junto à população.

Poder-se-ia afirmar que o Serviço Social, como profissão inscrita na divisão social do trabalho, situa-se no processo de reprodução das relações sociais, fundamentalmente como uma atividade auxiliar e subsidiária no exercício do controle social e na difusão da ideologia da classe dominante junto à classe trabalhadora (IAMAMOTO; CARVALHO, 1991, p. 94).

A concepção do Serviço Social como "[...] uma especialização do trabalho, uma profissão inserida na divisão social e técnica do trabalho coletivo em sociedade [...]" (IAMAMOTO, 1999, p. 22), se reporta ao entendimento de que as transformações ocorridas no mundo do trabalho afetam não só as demais especializações do trabalho, como também a atividade do assistente social. Ainda que seja um intelectual mediador (IAMAMOTO; CARVALHO, 1991), esse profissional também é afetado pelas novas mudanças adensadas pelo capital, as quais, circunscritas nas bases produtivas, dão forma a um novo padrão de organização e gestão do trabalho.

Nessa medida, os retrocessos desencadeados pelo capitalismo contemporâneo podem ser evidenciados no cotidiano do trabalho do assistente social que observa o impacto dessas mudanças em suas próprias relações de trabalho. A isto se vincula, ainda, a questão de que o sucateamento das políticas sociais, associado ao progressivo desemprego, às pressões por flexibilização e restrição de direitos no campo do trabalho, aprofundam a desigualdade social por um lado e, por outro, tornam também precários os serviços sociais.

Raichelis (2011) argumenta que, em virtude dos impactos da reestruturação produtiva nas condições de vida e saúde dos trabalhadores, percebe-se volume expressivo de estudos de

Temporalis, Brasília (DF), ano 19, n. 37, p. 84-101, jan./jun. 2019. | ISSN 2238-1856 


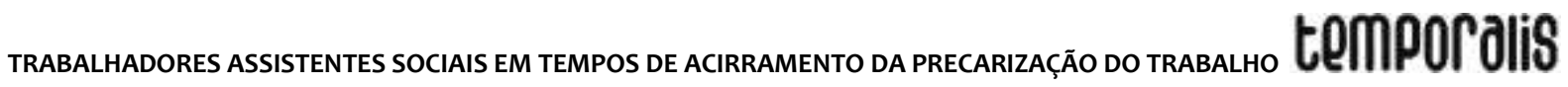

assistentes sociais que se indignam em face da exploração a que os trabalhadores se encontram submetidos. No entanto, deflagra-se na referência profissional a esse objeto de análise uma relação exterior, desprovida da concepção de sujeitos da mesma classe. Vejamos:

\begin{abstract}
Verifica-se a mesma tendência no debate sobre a saúde do trabalhador. De modo geral, as pesquisas e análises sobre trabalho e saúde, ou mais propriamente sobre o adoecimento dos trabalhadores decorrente das condições em que realiza seu trabalho, são relações problematizadas a partir da sua incidência na classe trabalhadora, não incluído aí o assistente social como sujeito vivo do trabalho social, sendo quase inexistentes estudos e pesquisas que tomam como objeto os próprios profissionais que sofrem e adoecem a partir do cotidiano de seu trabalho e da violação de seus direitos (RAICHELIS, 2011, p. 426).
\end{abstract}

Tais apontamentos remetem à reflexão sobre a necessidade de se debruçar sobre a própria realidade de trabalho, compreendendo o assistente social também como trabalhador assalariado, inserido na divisão social e técnica do trabalho (IAMAMOTO, 1999). Isto é, o desafio de analisar as estratégias sutis do capitalismo que afetam o cotidiano de trabalho desse profissional, moldando-o por meios velados, com o fito de contribuir para o processo de se alcançar lucro constante. De outro modo, Santos e Stampa (2017) destacam que essa inquietação se constitui uma demanda do presente:

[...] observa-se que, na realidade, estamos diante de um discurso fetichizado, onde o que se intenta é aplicar reformas trabalhistas que se traduzem nas mais perversas medidas 'antitrabalhistas'. Busca-se com esse discurso difundido pelo Estado, a adesão, sem conflitos, dos trabalhadores ao interesse patronal em violar e suprimir os direitos sociais já instituídos (SANTOS; STAMPA, 2017, p. 55).

O entendimento do assistente social como trabalhador especializado, que, como qualquer outro trabalhador, vende sua força de trabalho no mercado profissional em troca de um salário é, portanto, imprescindível, para que através da própria vivência, da experiência profissional, sejam planejadas ações eficazes, mais condizentes, também, com a garantia dos direitos dos trabalhadores usuários dos serviços.

Nesse sentido, Freire (2010) acrescenta que o avanço nos mecanismos de controle social frente à contradição existente nos diferentes espaços de trabalho e sua superação demanda fortalecimento no que tange à articulação com os movimentos sociais e organizações mais autônomas de trabalhadores. A superação de expressões da questão social relacionadas ao trabalho, que afetam os diversos trabalhadores das diferentes categorias profissionais, demanda a construção de uma identidade ampliada de classe. Isso requer "[...] um longo processo de maturação, para maior qualidade do processo de politização. Este inclui a análise das opções políticas além das aparências e da mídia dominante [...]" (FREIRE, 2010, p. 307).

A relevância dos estudos que caminham nesta direção se encontra na possibilidade de produzirem contribuições para o debate sobre o assunto, suprimindo a lacuna existente neste campo temático. Acredita-se que por meio da realização de pesquisas sobre o trabalho do assistente social, outras contribuições se tornarão viáveis como proposições atuais para o fortalecimento da organização dos assistentes sociais enquanto sujeitos trabalhadores. 
Isso posto, pode-se afirmar que um dos desafios dessa categoria profissional se encontra no aprofundamento da análise sobre os processos de trabalho nos quais o Serviço Social se insere, compreendendo o assistente social também como trabalhador e sujeito social em sua totalidade.

lamamoto complementa essa discussão, sintetizando que é necessária a análise da profissão em sua totalidade, sob o risco de se obter uma visão unilateral da realidade:

[...] Em síntese, o Serviço Social é considerado como uma especialização do trabalho e a atuação do assistente social uma manifestação de seu trabalho, inscrito no âmbito da produção e reprodução da vida social. Esse rumo da análise recusa visões unilaterais, que apreendem dimensões isoladas da realidade, sejam elas de cunho economicista, politicista ou culturalista. A preocupação é afirmar a ótica da totalidade na apreensão da dinâmica da vida social, identificando como o Serviço Social se relaciona com as várias dimensões da vida social (IAMAMOTO, 1999, p. 27).

Tendo por referência a política econômica adotada no país, calcada no modelo neoliberal, entende-se que, no contexto atual, onde existir força de trabalho vivo e relações de trabalho baseadas no processo de acumulação do capital haverá a necessidade do desenvolvimento de potencialidades em direção a uma consciência crítica e reflexiva, frente às condições de vida e de trabalho. Assim, considera-se imprescindível para a intervenção qualificada, no presente, a acepção crítica sobre os desafios postos ao trabalhador assistente social na contemporaneidade.

\section{TRABALHADORES ASSISTENTES SOCIAIS E SEUS DESAFIOS EM TEMPOS DE ACIRRAMENTO DA PRECARIZAÇÃO DO TRABALHO}

[...] o momento em que vivemos é um momento pleno de desafios. Mais do que nunca é preciso ter coragem, é preciso ter esperanças para enfrentar o presente. $E$ ́ preciso resistir e sonhar (IAMAMOTO, 1999, p. 17).

Os retrocessos desencadeados pelo capital atingem diretamente a classe trabalhadora. Disso depreende-se que a articulação entre a reestruturação produtiva e a instituição de um Estado neoliberal se traduzem em consequências nefastas para o conjunto dos trabalhadores, impactando, também, o trabalho e a própria vida dos assistentes sociais.

Nessa medida, no processo de desenvolvimento deste estudo, deparou-se com a formatação de novos tipos de trabalho do assistente social que se alinham a essa nova ordenação do capital. Disso decorre que diferentes expressões de precarização do trabalho do assistente social são disseminadas na contemporaneidade.

No intento de descortinar o real, observou-se que, sob a roupagem do moderno, e imiscuídas no discurso de que são importantes porque se constituem oportunidades de trabalho para os assistentes sociais, novas formas de precarização do trabalho podem ser assimiladas. À vista disso, merece destaque a pesquisa desenvolvida por Gomes (2015a; 2015b), que teve por objeto o estudo de duas modalidades de consultoria externas contemporâneas, desveladas como duas expressões atuais do trabalho precarizado do assistente social que predominam nas empresas que operam no território nacional. 


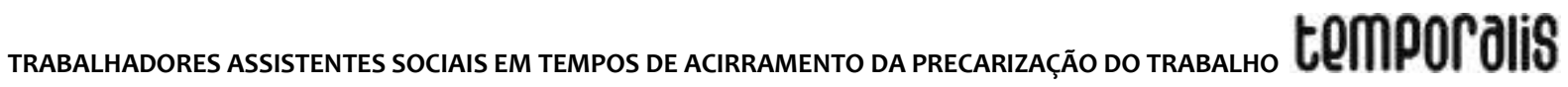

Estas modalidades de consultoria, cabe mencionar, se destacam pelo grau de absorção da força de trabalho dos assistentes sociais e por dotarem de significado inverso o sentido original do termo, sobretudo se considerada a concepção adotada sobre consultoria em Serviço Social. ${ }^{2}$

Verificando-se o valor semântico da palavra consultoria, entende-se que o termo se refere ao parecer concedido por profissional ou empresa reputada especialista em determinado assunto. Nas palavras de Vasconcelos, é assim que se constitui a consultoria:

Frequentemente para que uma equipe ou assistente social solicite um processo de consultoria, é necessário que já tenha passado, ainda que precariamente, pela elaboração de um projeto de prática, objetivando, com a consultoria, respostas para algumas questões pontuais que dificultam o encaminhamento do mesmo (VASCONCELOS, 1998, p. 128).

De acordo com Gomes (2015a), no universo dessas consultorias externas, existem, por um lado, as especialistas em Programas de Assistência ao Empregado (PAE) e, por outro, as especialistas em Serviço Social. Em ambas as frentes, o Serviço Social se insere como uma forma de atendimento aos trabalhadores. Dessa maneira, o assistente social, de uma ou outra forma, presta serviço para uma empresa.

Vale dizer, no entanto, que o assistente social se vincula às empresas, na forma da prestação do serviço de assessoria por diversas formas, "[...] com ou sem carteira assinada" (GOMES, 2015a, p. 372). Desse modo, são observadas, nesses modelos de assessorias prestadas por trabalhadores assistentes sociais, formas mais tradicionais de terceirização, vínculos flexíveis e informais de trabalho.

Quanto a primeira frente, se refere às empresas de assessoria que desenvolvem os PAE's, onde são organizados módulos de atendimentos focais, efetuados por especialistas de diversas áreas do conhecimento contratados por essas instituições. As empresas que compram os serviços de assessoria "[...] escolhem as modalidades que irão compor aos seus programas" (GOMES, 2015a, p. 372). Nessa modalidade, por meio da assessoria, o Serviço Social se insere neste espaço sócio-ocupacional como uma das especialidades de atendimento dentre outras alternativas.

Assim, nos PAE's, as denominadas assessorias se traduzem em atendimentos pontuais. $\mathrm{O}$ atendimento denominado focal pode também ser chamado de breve e, como se não bastasse essa limitação, estas assessorias estão subordinadas ao controle do tempo do atendimento destinado ao trabalhador: "[...] o serviço limita o número de atendimentos por questão a ser solucionada. Nessa modalidade o trabalhador não dispõe de tempo indeterminado para o atendimento de suas necessidades" (GOMES, 2015a, p. 372).

Em vista disso, pode-se inferir que a forma de assessoria que insere o Serviço Social nos PAE's apresenta risco de que sejam resgatadas, por algumas assistentes sociais, práticas funcionalistas, com propostas de ajustamento social, similares às adotadas de maneira recorrente antes da adoção do atual projeto profissional crítico do Serviço Social. Por outro

\footnotetext{
${ }^{2}$ É por esta razão que, ao fazer referência às chamadas assessorias, as quais representam formas de terceirização e precarização do trabalho do assistente social, foram inseridas aspas à palavra, alinhando-se às ponderações da autora citada.
}

Temporalis, Brasília (DF), ano 19, n. 37, p. 84-101, jan./jun. 2019. | ISSN 2238-1856 
lado, as limitações impostas por este serviço, sugerem outra direção divergente da proposta pelo projeto ético-político do Serviço Social.

No que se refere à segunda modalidade citada, trata-se das denominadas "[...] consultorias externas especializadas em Serviço Social" (GOMES, 2015a, p. 373). Nestas, os programas e projetos são construídos conforme as requisições das empresas, mas não predefinidos totalmente, apresentando certa maleabilidade em sua elaboração, o que a difere do modelo anterior. Além disso, este modelo não tem a forma de atuação focal nem delimita o número de atendimentos realizados pelas assessorias como o primeiro.

Embora o segundo modelo se apresente mais flexível no que se refere às imposições institucionais, verifica-se que se mantém descolado do projeto profissional do Serviço Social, uma vez que, dentre outros elementos, cerceia a autonomia do assistente social, categoria que tem um compromisso expresso com a classe trabalhadora. Um exercício profissional conectado aos princípios éticos do Serviço Social tem como norte a propositura de ações criativas, visando o apoio à auto-organização dos trabalhadores em direção ao atendimento de seus interesses e necessidades.

Isso pressupõe cooperar para a alteração da correlação de forças institucionais, contribuindo para que as reais demandas dos trabalhadores sejam contempladas. Em outras palavras, é a criação de projetos e programas com a participação dos usuários e para os usuários dos serviços sociais. Essa assertiva pressupõe ainda o reconhecimento dos usuáriose dos assistentes sociais como sujeitos trabalhadores integrantes da mesma classe. Conforme o artigo $4^{\circ}$, inciso VIII da Lei de Regulamentação da Profissão (Lei 8.662/93), compete ao assistente social "[...] prestar assessoria e consultoria a órgãos da administração pública direta e indireta, empresas privadas e outras entidades, com relação às matérias relacionadas no inciso II deste artigo" (CONSELHO FEDERAL DE SERVIÇO SOCIAL, 1993, p. 45). Assim, fazendo referência a competência descrita no inciso II, temos a seguinte atribuição: "[...] elaborar, coordenar, executar e avaliar planos, programas e projetos que sejam do âmbito de atuação do Serviço Social com participação da sociedade civil" (CONSELHO FEDERAL DE SERVIÇO SOCIAL, 1993, p. 44).

A apropriação dessas análises relativas ao campo empresarial se fizeram necessárias para elucidar o pano de fundo dessas novas relações de trabalho estabelecidas no cotidiano do conjunto da classe trabalhadora, as quais também atravessam o trabalho do assistente social. Percebe-se que elas não são dadas ao acaso; pelo contrário, são instituídas estrategicamente, com a cooptação dos trabalhadores, inclusive dos assistentes sociais, como também os sujeitando a extrema exploração, visto que não dispõem de alternativas para atenderem suas condições objetivas de sobrevivência.

Apesar dos aspectos que diferenciam um modelo de assessoria do outro, ambos compõem um conjunto de interesses do mercado, principalmente no que concerne aos custos provenientes da relação de compra e venda da força de trabalho. Neste circuito, é oportuno dizer que novas formas de precarização de trabalho se avultam no século XXI sob o fetiche do novo, do inovador, atravessando diferentes espaços socio-ocupacionais e requisitando diferentes trabalhadores, sendo estes, também, os trabalhadores assistentes sociais. 


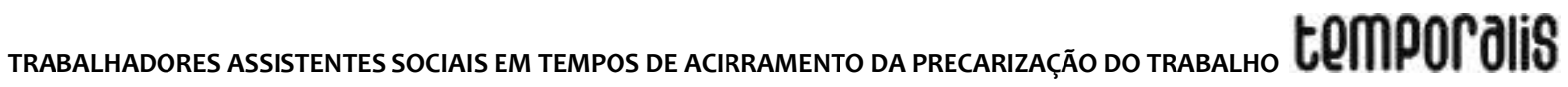

Outra forma contemporânea de vínculo precário do trabalho dos assistentes sociais diz respeito à contratação por meio de pregão. Nessa forma de contratação, via de regra, o órgão público (forma de contratação mais difundida em municípios do interior do Estado), divulga por meio de edital a contratação de assistentes sociais. Assim, é aberta a livre concorrência entre os assistentes sociais no que concerne à venda de sua força de trabalho, ocupando as vagas aqueles que oferecem menor preço pela oportunidade de trabalho. ${ }^{3}$

Tal fato também foi evidenciado por Costa (2014) em suas análises sobre o trabalho dos assistentes sociais nos municípios cearenses:

Além disso, outro elemento encorpa essa situação, como o do modelo adotado
por alguns municípios cearenses que abrem processo licitatório do tipo menor
preço para contratar assistentes sociais. O profissional segue na data e horário
previsto para a abertura dos envelopes nos quais estão escritos os preços dados
pelos assistentes sociais e é contratado aquele que lança o menor preço da sua
força de trabalho. Essa situação foi verificada em publicação no Diário Oficial do
Estado do Ceará, que divulgava a licitação em um determinado município (COSTA,
2014, p. 372).

Nessa linha, cumpre destacar que a desqualificação e desregulamentação do trabalho do assistente social são naturalizadas nos processos de fetiche do capital que se expandem no país. Isto confirma as colocações de Antunes $(1996,2008)$, assim como as de lamamoto (1999, 2007), as quais discorrem sobre a dinâmica atual de espoliação do conjunto dos trabalhadores imiscuída em novas formas de organização e realização do trabalho.

Em análise sobre o assunto, Silva (2013) exemplifica a complexidade dessa tendência atual que se espraia no estado do Ceará e incide sobre os trabalhadores assistentes sociais:

Outro aspecto que parece indicar a referida naturalização foi o episódio ocorrido em relação ao estágio supervisionado em Serviço Social. Conforme citamos, a região conta com três cursos de Serviço Social, o que implica muitos alunos em campo de estágio. O Conselho Regional de Serviço Social (CRESS) do Ceará determinou que fossem suspensos os estágios realizados em Instituições cujos (as) profissionais não tivessem vínculos permanentes com a Instituição, justamente em decorrência da grande quantidade de profissionais atuando na modalidade de serviços prestados. A suspensão não durou 15 dias, dado o reconhecimento do CRESS de que praticamente todos os espaços sócioocupacionais têm assistentes sociais trabalhando nessas condições de contrato temporário, via licitação (SILVA, 2013, p. 126).

Sobre essa e outras formas atuais de precarização do trabalho do assistente social, Costa (2014, p.372) menciona, com base em pesquisa realizada com assistentes sociais no município de Fortaleza/CE, que determinadas instituições contratam assistentes sociais como assistentes técnicos para realizarem atribuições específicas de assistentes sociais.

\footnotetext{
${ }^{3}$ Por meio de pesquisa junto às plataformas digitais de diferentes unidades federativas, pode ser observado o lastramento da precarização do trabalho do assistente social com os contratos de trabalho firmados através de pregão. No Estado do Rio de Janeiro podemos mencionar o pregão realizado pela Universidade Federal Rural do Rio de Janeiro (UFRRJ), conforme edital publicado no ano de 2012 (UFRRJ, 2012). Além deste, podemos citar o recente pregão realizado no município de São Pedro da Aldeia (PREFEITURA MUNICIPAL DE SÃO PEDRO DA ALDEIA, 2017).
}

Temporalis, Brasília (DF), ano 19, n. 37, p. 84-101, jan./jun. 2019. | ISSN 2238-1856 
Assim, além de desqualificarem o trabalho do assistente social, se apropriam dessa estratégia como meio de baratear a mão de obra deste trabalhador.

Diante desse quadro, Costa(2014, p. 372) afirma que :

Outro fenômeno de grande relevância nesse processo é a crescente terceirização, que ganha espaço nas instituições públicas do Estado. Este fenômeno vem também afligindo uma parte significativa de profissionais do Serviço Social que ingressa no mercado de trabalho por essa via e por contratos temporários, a exemplo das entrevistadas da pesquisa realizada com as profissionais da Rede de Atendimento à Mulher em Situação de Violência do município de Fortaleza/CE: das seis, apenas duas eram concursadas, as outras eram terceirizadas, e ainda havia os casos nos quais as profissionais eram contratadas como assistentes técnicas e exerciam a função de assistente social (COSTA, 2014, p. 372).

Com base nesses exemplos, podemos aduzir que estamos diante de uma lógica de mercadorização das políticas sociais, das relações de trabalho, enfim, da própria vida, que abarca o conjunto dos trabalhadores, inclusive os assistentes sociais. Dessa forma, desvelar os mecanismos ocultos de acumulação do capital que se concentram na expropriação do trabalho e da própria vida dos trabalhadores é, portanto, um imperativo no Serviço Social.

Esse debate nos reporta às análises desenvolvidas no âmbito do Serviço Social, sobretudo se observarmos as questões que envolvem os processos de trabalho nos quais os assistentes sociais se encontram inseridos. Nessa medida, cabe ressaltar o documento denominado Parâmetros para a atuação de assistentes sociais na saúde, publicado pelo Conselho Federal de Serviço Social (CONSELHO FEDERAL DE SERVIÇO SOCIAL, 2010) como resultado das reflexões coletivas da categoria. Ele nos adverte quanto ao desmonte das políticas públicas de saúde na conjuntura atual e à necessidade de articulação política entre o conjunto da classe trabalhadora:

\begin{abstract}
A nova configuração da política de saúde vai impactar o trabalho do assistente social em diversas dimensões: nas condições de trabalho, na formação profissional, nas influências teóricas, na ampliação da demanda e na relação com os demais profissionais e movimentos sociais. Amplia-se o trabalho precarizado e os profissionais são chamados a amenizar a situação da pobreza absoluta a que a classe trabalhadora é submetida (CONSELHO FEDERAL DE SERVIÇO SOCIAL, 2010, p. 23).
\end{abstract}

Esta reflexão, embora recortada no campo da saúde, nos traz inquietações sobre o trabalhador assistente social na contemporaneidade. A política de saúde representa o espaço que tem garantido maior empregabilidade para os trabalhadores assistentes sociais na atualidade, seguida pelas políticas de assistência social, previdência social, habitação, educação e o campo sociojurídico (ALMEIDA; ALENCAR, 2015). Entendendo que este é um trabalhador inserido na divisão social e técnica do trabalho e, ainda, um operador de políticas públicas, além do impacto sofrido diretamente em suas condições de trabalho, não seria afetado também pela precarização do trabalho e sucateamento de políticas públicas que atingem outros sujeitos trabalhadores usuários de seus serviços?

Não obstante esses conflitos, presentes no cotidiano do trabalho, pontua-se que a desconsideração sobre a importância de estudos e atenção sobre as relações e condições de trabalho do assistente social, bem como sobre os processos velados de violação dos direitos desses trabalhadores, nos diversos espaços socio-ocupacionais, podem implicar na

Temporalis, Brasília (DF), ano 19, n. 37, p. 84-101, jan./jun. 2019. | ISSN 2238-1856 


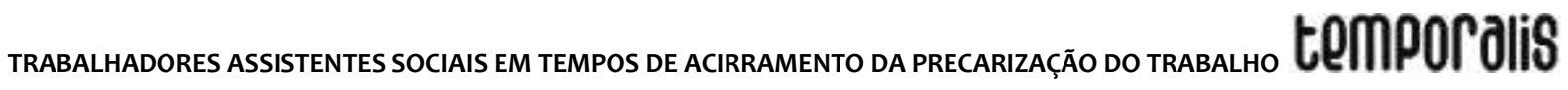

redução do próprio fundo de vida destes (LUCE, 2013). Isto é, as novas conformações do mundo do trabalho, que tendem a espoliar gradativamente a força de trabalho com mais intensidade, através de diferentes estratégias, comprometem a força física e psíquica do trabalhador a tal ponto que se apropriam até mesmo da expectativa de vida destes sujeitos.

A invisibilidade desses processos de apropriação da força de trabalho pelo capital, como mercadoria que deve ser explorada ao extremo, reifica e aprofunda as diferentes formas de precarização do trabalho, inclusive dos assistentes sociais. Nessa medida, descortinar os processos aviltantes de trabalho nos quais os assistentes sociais se encontram inseridos pode significar, com o mesmo peso, a defesa dos direitos humanos:

\begin{abstract}
Assim, direitos humanos se relacionam a necessidades como saúde; educação; assistência social; moradia digna; liberdade de expressão; participação política; direito de ir e vir; liberdade religiosa ou de não ter confissão religiosa; livre orientação e expressão da diversidade sexual; igualdade de gênero; igualdade étnico-racial; direitos do mundo do trabalho; direito à terra e à cidade e inúmeras outras dimensões da vida dos sujeitos sociais. (CRESS/7 REGIÃO, 2013, p.4). (grifos nossos).
\end{abstract}

Em face dessas análises, está posto, particularmente ao assistente social, o desafio de atuar na contramão das tendências que redundam em devastadoras violações de direitos dos trabalhadores. O compromisso ético-político desta categoria profissional exige a denúncia desses processos fetichizados pelo capital no cotidiano dos trabalhadores (IAMAMOTO, 2007). Isto também demanda "[...] a pesquisa como transversal ao trabalho profissional" (OLIVAR, 2010, p. 131).

Disso decorre que compreender amplamente as condições e relações de trabalho do assistente social, na atualidade, pressupõe também buscar compreender a dimensão subjetiva de sua intervenção. Isto é, perceber a forma como esse profissional identifica o significado do seu trabalho e em que direção política se apoia a sua intervenção profissional. Esta consideração se torna importante na medida em que as respostas profissionais apresentadas pelos trabalhadores assistentes sociais, inseridos nos diferentes espaços socio-ocupacionais, estão intrinsecamente vinculadas aos seus valores, às suas concepções, bem como ao seu posicionamento ético-político.

A conformação do trabalho do assistente social se constitui num complexo mixde condições objetivas e subjetivas que exige ir além das aparências para decifrá-lo. Desta forma, Guerra (2007a, p. 3) afirma que:

Neste âmbito, o processo de trabalho é compreendido como um conjunto de atividades prático-reflexivas voltadas para o alcance de finalidades, as quais dependem da existência, da adequação e da criação dos meios e das condições objetivas e subjetivas (GUERRA, 2007a, p. 3).

Nesse sentido, depreende-se que os desafios atuais postos ao trabalhador assistente social são maiores, uma vez que a alteração das requisições profissionais ocorre, paralelamente, ao sucateamento das políticas públicas, afetando diretamente o exercício profissional do assistente social, visto que este se constitui também um executor de políticas públicas. 
Assim, acredita-se, a intervenção qualificada, competente, propositiva, a qual, além de ser prevista no Código de Ética Profissional do Serviço Social (CONSELHO FEDERAL DE SERVIÇO SOCIAL, 1993), constitui-se demanda do nosso cotidiano. Para Guerra (2007b, p.16), este é o principal desafio da categoria:

Aqui se localiza o desafio central para o assistente social, que é o de fazer a crítica dos fundamentos da cotidianidade, tanto daquela em que ele se encontra inserido quanto a do cotidiano dos sujeitos sociais a quem presta serviços, o que significa examinar os fundamentos, analisá-los, reconhecê-los, para transcendê-los (GUERRA, 2007b, p. 16).

A materialização de um trabalho nesta direção, portanto, torna imprescindível a pesquisa sobre os fenômenos sociais envolvidos nesse processo. Em acordo com esse entendimento, lamamoto (2007) afirma que:

\footnotetext{
Nos diferentes espaços ocupacionais do assistente social é de suma importância impulsionar pesquisas e projetos que favoreçam o conhecimento do modo de vida e de trabalho - e correspondentes expressões culturais - dos segmentos populacionais atendidos, criando um acervo de dados sobre os sujeitos e as expressões da questão social que as vivenciam. O conhecimento criterioso dos processos sociais e de sua vivência pelos indivíduos sociais poderá alimentar ações inovadoras [...]. Esse conhecimento é pré-requisito para impulsionar a consciência critica e uma cultura pública democrática para além das mistificações difundidas pela prática social em geral e particularmente pela mídia [...] (IAMAMOTO, 2007, p. 200).
}

Nisto também reside a visão de que, sendo qualificado como trabalhador especializado (IAMAMOTO, 1999), o assistente social se encontra inserido nesta realidade, seja como sujeito trabalhador, imbricado na relação entre patrão e empregado, seja como operador terminal de políticas sociais (NETTO, 1992), seja como profissional competente na gestão da política social (MATOS, 2006). Daí a necessidade de permanente análise sobre a realidade na qual se inserem os trabalhadores assistentes sociais, desvelando seus aspectos determinantes.

Nesses termos, é a partir da dinâmica contraditória da realidade que se encontram alternativas consoantes à construção de um novo padrão de sociabilidade democrática, onde se perceba a efetiva consolidação dos direitos sociais e humanos. Para tanto, lamamoto (2007) afirma que é necessário um profissional com "[...] perfil profissional culto, crítico, e capaz de formular, recriar e avaliar propostas que apontem para a progressiva democratização das relações sociais" (IAMAMOTO, 2007, p. 208). Isso requer compromisso ético-político e análise da realidade baseada na teoria crítica.

Somada a essas ferramentas, a pesquisa da realidade permitirá "[...] decifrar as situações particulares com que se defronta o assistente social no seu trabalho, de modo a conectálas aos processos sociais macroscópicos que as geram e as modificam." (IAMAMOTO, 2007, p. 208).

\section{CONCLUSÃO}

As mudanças operadas no universo do trabalho, forjadas pelo processo de reestruturação produtiva desencadeado no Brasil, sobretudo a partir da década de 1990, dá forma a um 


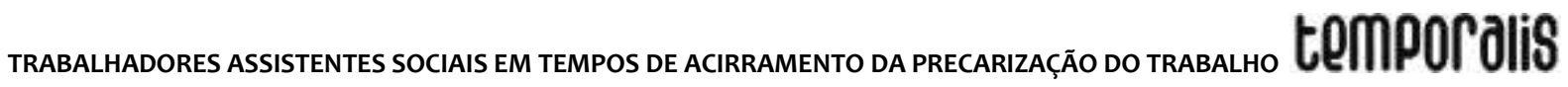

novo modelo de sociabilidade que rege não apenas as relações de trabalho, mas também os demais âmbitos da vida social. Como corolário, assiste-se a expansão do fenômeno da acumulação flexível que se traduz efetivamente em total desregulação das relações de trabalho e garantias trabalhistas, ao passo em que, pela máxima exploração do trabalho é que se produz o acúmulo de riqueza.

Diante dessa lógica, se sobressaem os altos níveis de desemprego, evidenciando seu caráter estrutural. Além disso, lastreia-se o trabalho precarizado, o subemprego, uma vez que os diversos trabalhadores não vislumbram alternativas à sujeição a essas formas de exploração para se manterem vivos.

Tais fatos, além de submeterem a própria vida ao trabalho, resultam na fragmentação dos trabalhadores, visto que têm a sua organização política prejudicada seja pelo domínio do seu tempo, seja pela produção da insegurança e receio do desemprego, seja pela incorporação da ideologia burguesa dominante que gera a resignação. Ao se constatar essas evidências, desencadeadas pelas mudanças nos processos produtivos que afetam amplamente as relações de trabalho e seus operadores, percebe-se que daí decorre, também, a necessidade de descortinar esse processo pela pesquisa, pelo debate, pela proposição de ações que promovam o fortalecimento das resistências do conjunto de trabalhadores, sujeitos coletivos desse processo.

Não obstante, superar a superexploração da força de trabalho pelo capital por um lado e, por outro, o tecnicismo, a refuncionalização do conservadorismo, não é tarefa fácil. Contudo, deve-se ter sempre em vista que a mesma realidade que oprime os trabalhadores é a que lhes oferece subsídios para a construção de novos horizontes transformadores, e é nesta perspectiva que devem buscar apoio.

Cumpre destacar aqui a necessidade de envolvimento e compromisso com a temática trabalho do assistente social, inclusive nas entidades de ensino e pesquisa. Esta se constitui uma demanda do presente para o alcance de dados concretos, extraídos da realidade atual, que possam subsidiar, também, políticas públicas no processo de formação dos assistentes sociais, assim como no que concerne à proteção aos seus direitos sociais do trabalho (e por que não?).

De outro modo, refletir sobre os impactos dos processos atuais, com a exacerbação de aspectos conservadores e reacionários, que incidem sobre o trabalho do assistente social precarizando-o, requer, na mesma medida, pensar em alternativas à intensiva exploração que também afeta os assistentes sociais. Nessa medida, discutir sobre o trabalho dos assistentes sociais implica, também, em pensar sobre o seu cotidiano de trabalho, sua conformação no contexto brasileiro atual, descortinando, inclusive, suas particularidades regionais.

Em tempos de capital fetiche (IAMAMOTO, 2007), urge o levantamento e a publicização de questões que envolvem as relações de trabalho, suas condições e processos, na atualidade. Observa-se que são esses elementos que permitem ações necessárias para a construção de espaços de trabalho mais saudáveis, alinhadas ao enfrentamento das múltiplas formas de violações dos direitos humanos e que correspondam aos interesses e necessidades da classe trabalhadora, incluindo aí o assistente social.

Temporalis, Brasília (DF), ano 19, n. 37, p. 84-101, jan./jun. 2019. | ISSN 2238-1856 


\section{REFERÊNCIAS}

ASSOCIAÇÃO BRASILEIRA DE ENSINO E PESQUISA EM SERVIÇO SOCIAL (ABEPSS). História. Brasília (DF), @2019. Disponível em: http://www.abepss.org.br/historia-7. Acesso em: 28 mar. 2018.

ALMEIDA, Ney Luiz Teixeira de; ALENCAR, Mônica Maria Torres de. Serviço Social e trabalho: particularidades do trabalho do assistente social na esfera pública estatal brasileira. O Social em Questão, Rio de Janeiro: PUC-Rio, ano 18, n. 34, p. 161-180, 2015.

ANTUNES, Ricardo. Adeus ao Trabalho?: ensaio sobre as metamorfoses e a centralidade do Mundo do trabalho. 13. ed. São Paulo: Cortez, 2008.

ANTUNES, Ricardo. Dimensões da crise e metamorfoses do mundo do trabalho. Serviço Social e Sociedade, Rio de Janeiro, n. 50, p. 78-86, abr. 1996.

CARVALHO, Márcia Helena de. O Serviço Social como trabalho: afirmação que ainda provoca debates no interior da profissão. In: SIMPÓSIO MINEIRO DE ASSISTENTES SOCIAIS, 4., 2016, Belo Horizonte. Anais [...]. Belo Horizonte: Conselho Regional de Serviço Social, 2016. Disponível em: http://cress-

mg.org.br/hotsites/Upload/Pics/45/45362b02-bd65-405d-95d4-d8a37de5c2f1.pdf. Acesso em: 22 set. 2018.

CONSELHO FEDERAL DE SERVIÇO SOCIAL (CFESS). Código de ética do/a assistente social. Lei8.662/93 de regulamentação da profissão. Brasília: ConselhoFederal de Serviço Social, 1993.

CONSELHO FEDERAL DE SERVIÇO SOCIAL (CFESS). Parâmetros para a atuação de assistentes sociais na saúde. Brasília (DF): CFESS, 2010.

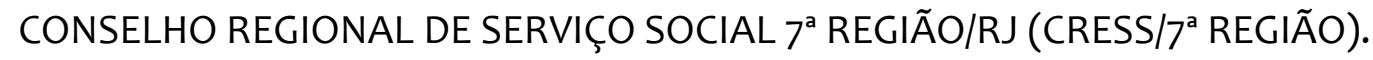
Contribuições para um exercício profissional comprometido com a defesa dos direitos humanos. Cartilha. Rio de Janeiro: CRESS, 2013.

COSTA, Gilmaísa M. Serviço Social em debate: ser social, trabalho e ideologia. Maceió: Edufal, 2011.

COSTA, Gilmaísa M. Aproximação ao Serviço Social como complexo ideológico. Temporalis, Brasília (DF): ABEPSS, v.2, p. 95-117, 2000.

COSTA, Renata Gomes da. A práxis do/a assistente social e a materialização do Projeto Ético-Político na sociedade capitalista. Textos e Contextos, Porto Alegre, v. 13, n. 2, p. 366378, jul./dez. 2014.

FREIRE, Lúcia M. de B. Movimentos sociais e controle social em saúde do trabalhador: inflexões, dissensos e assessoria do Serviço Social. Serviço Social e Sociedade, São Paulo, n. 102, abr./jun., 2010. 


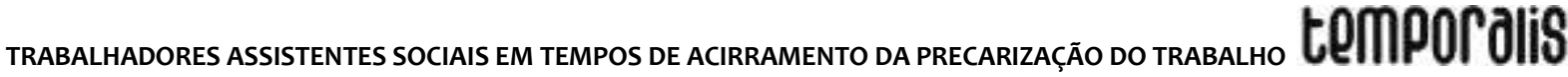

GOMES, Márcia Regina Botão. Consultoria social nas empresas: entre a inovação e a precarização silenciosa do Serviço Social. Serviço Social e Sociedade, São Paulo, n. 122, p.357-380, abr./jun. 2015a.

GOMES, Márcia Regina Botão. Serviço Social e consultoria empresarial: uma possibilidade de intervenção crítica? 2015. Tese (Doutorado em Serviço Social)- Programa de Pós-Graduação em Serviço Social da Universidade do Estado do Rio de Janeiro, Rio de Janeiro, 2015b.

GUERRA, Yolanda. A instrumentalidade no trabalho do assistente social. Belo Horizonte, 2007a. Disponível em: http://www.cedeps.com.br/wp-content/uploads/2009/06/YolandaGuerra.pdf. Acesso em: 20 set. 2018.

GUERRA, Yolanda. O projeto profissional crítico: estratégia de enfrentamento das condições contemporâneas da prática profissional. Serviço Social e Sociedade, São Paulo, n. 91 , p. 5-33, 2007b.

IAMAMOTO, Marilda Villela. Serviço Social em tempo de capital fetiche: capital financeiro, trabalho e questão social. São Paulo: Cortez, 2007.

IAMAMOTO, Marilda Villela. O serviço social na contemporaneidade: trabalho e formação profissional. São Paulo: Cortez, 1999.

IAMAMOTO, Marilda Villela; CARVALHO, Raul. Relações sociais e serviço social no Brasil: esboço de uma interpretação histórico-metodológica. 8. ed. São Paulo: Cortez, 1991.

LESSA, Sérgio. Serviço Social e trabalho: porque o Serviço Social não é trabalho. 2. ed. São Paulo: Instituto Lukács, 2012.

LESSA, Sérgio. Serviço Social e trabalho: do que se trata? Temporalis, Brasília (DF): ABEPSS, v.1, n.1 p. 35-58, 2000.

LUCE, Mathias Seibel. Brasil: nova classe média ou novas formas de superexploração da classe trabalhadora? Trabalho, Educação e Saúde, Rio de Janeiro, v. 11, n. 1, p. 145-166, jan./abr. 2013.

MARX, Karl. O Capital: crítica da economia política. Livro Primeiro, Tomo 1. 2. ed. São Paulo: Nova Cultural, 1985. (Os Economistas).

MARX, Karl. O Capital. Livro I, Capítulo VI (inédito). 2. ed. São Paulo: Ciências Humanas, 1978.

MATOS, Maurílio Castro de. Assessoria e consultoria: reflexões para o Serviço Social. In: BRAVO, M. I. S.; MATOS, M. C. de. Assessoria, consultoria e Serviço Social. Rio de Janeiro: 7 Letras, 2006.

NETTO, José Paulo. Capitalismo monopolista e Serviço Social. São Paulo: Cortez, 1992. 
OLIVAR, Mônica Simone Pereira. O campo político da saúde do trabalhador e o Serviço Social. Serviço Social e Sociedade, São Paulo, n. 102, abr./jun., 2010.

PREFEITURA MUNICIPAL DE SÃO PEDRO DA ALDEIA. Pregão Presencial Nº 016/2017. Disponível em: http://webservice.npibrasil.com.br/wportal/arquivo.ashx?id=371d6920f3fa-45a3-b136-f62ae5ofcfcb. Acesso em 28 ago. 2018.

RAICHELIS, Raquel. O assistente social como trabalhador assalariado: desafios frente às violações de seus direitos. Serviço Social e Sociedade, São Paulo: Cortez, n. 107, p. 420437, 2011.

SANTOS, Flávia Barbosa Pardini; STAMPA, Inez. Medidas recessivas sobre os direitos dos trabalhadores no Brasil: breve esboço histórico sobre ofensivas e resistências. Libertas, Juiz de Fora, v. 17, p. 45-64, jan./jul./2017.

SILVA, Mossicléia Mendes da. Projeto ético-político e assistência social: um estudo do cotidiano de trabalho dos (as) assistentes sociais do Centro Sul / Vale do Salgado-CE. (Dissertação de mestrado)-Programa de Pós-Graduação em Serviço Social da Universidade do Estado do Rio de Janeiro, Rio de Janeiro, 2013.

STAMPA, Inez. Transformações recentes no "mundo do trabalho" e suas consequências para os trabalhadores brasileiros e suas organizações. Em Pauta, Rio de Janeiro, v. 10, n. 30, 2012.

UNIVERSIDADE FEDERAL RURAL DO RIO DE JANEIRO (UFRRJ). Edital de Seleção de Assistente Social. 2012. Disponível em: http://r1.ufrrj.br/graduacao/arquivos/Edital_Selecao_Assitente_Social.pdf. Acesso em 28 ago. 2018.

VASCONCELOS, Ana Maria. Relação Teoria/Prática: o processo de assessoria/consultoria e o Serviço Social. Serviço Social e Sociedade, São Paulo: Cortez, n. 56, p. 114-134, 1998.

Flávia Barbosa Pardini dos SANTOS trabalhou na concepção e delineamento das reflexões, realizando a revisão bibliográfica, bem como na redação do artigo, na sua revisão crítica e na aprovação da versão a ser publicada.

Graduada em Serviço Social pela Universidade Federal Fluminense (UFF), em 1997. Especialista em Serviço Social e Saúde pela Universidade Estadual do Rio de Janeiro (UERJ), em 2012. Mestre em Serviço Social pela Pontifícia Universidade Católica do Rio de Janeiro (PUC-Rio), em 2018. Atualmente é assistente social da Polícia Militar do Estado do Rio de Janeiro (PMERJ) e integrante do grupo de pesquisa Trabalho, Políticas Públicas e Serviço Social (TRAPPUS).

Inez STAMPA trabalhou na concepção e delineamento das reflexões, realizando a revisão bibliográfica, bem como na redação do artigo, na sua revisão crítica e na aprovação da versão a ser publicada.

Assistente Social. Doutora em Serviço Social pela PUC-Rio. Professora do Departamento de Serviço Social e do Programa de Pós-graduação em Serviço Social da PUC-Rio. Coordenadora Adjunta da área de Serviço Social da Capes. Bolsista de Produtividade em Pesquisa CNPq. 